\title{
First survey of ground-dwelling ants (Hymenoptera: Formicidae) on the uninhabited Gaja-jima Island, the Ryukyu archipelago, Japan
}

\author{
Motoki Katayama, Tadatsugu Hosoya \& Wataru Toki
}

Katayama, M., Hosoya, T. \& Toki, W. 2013: First survey of ground-dwelling ants (Hymenoptera: Formicidae) on the uninhabited Gaja-jima Island, the Ryukyu archipelago, Japan. — Entomol. Fennica 24: 216-222.

The ground-dwelling ant fauna on the uninhabited Gaja-jima Island, the Tokara Islands, the Ryukyu archipelago, Japan was investigated, which was the first survey on ants of the island. Twenty-three ant species were found during a visit of only eight hours in daytime. Four of them were new records to the Tokara Islands. Of the four new records, the southern limit of distributions was renewed for three species. Three exotic species, Pheidole fervens, Tetramorium bicarinatum, and Tapinoma melanocephalum were recognized, which seems relatively low given that ten exotic species have been altogether recorded from the Tokara Islands. The relationship between invasion by ants and the scale of human activity is discussed.

M. Katayama, Department of Ecology and Environmental Science, Graduate School of Agriculture, University of the Ryukyus, Nishihara, Okinawa, 9030213, Japan; The United Graduate School of Agricultural Sciences, Kagoshima University, 1-21-24 Kôrimoto, Kagoshima 890-0065, Japan; present address: Graduate School of Human and Environmental Studies, Kyoto University, Yosida-Nihonmatu, Sakyo ku, Kyoto, 6068501, Japan; E-mail: motok.k.ryuk @gmail.com

T. Hosoya, Division of Biodiversity Sciences, Faculty of Social and Cultural Studies, Kyushu University, 744 Motooka, Nishi-ku, Fukuoka, 819-0395 Japan W. Toki, Center for Ecological Research, Kyoto University, 2-509-3 Hirano, Otsu, Shiga 520-2113, Japan

Received 20 February 2013, accepted 1 July 2013

\section{Introduction}

Species checklists are fundamentals of many scientific studies and contribute to biodiversity conservation (Myers et al. 2000, Pfeiffer et al. 2011). However, they are recently considered as minor contributions to science, partly because of the low impact factor they achieve (Krell 2000). Unfortunately, species inventory remains insufficient es- pecially in places where diverse species would be expected like in tropical and sub-tropical regions (Myers et al. 2000).

The Tokara Islands consists of seven inhabited and five uninhabited islands located in the northern part of the subtropical Ryukyu archipelago (Fig. 1). They have been repeatedly connected and disconnected to Eurasia by the glacialinterglacial cycles, which make them interesting 

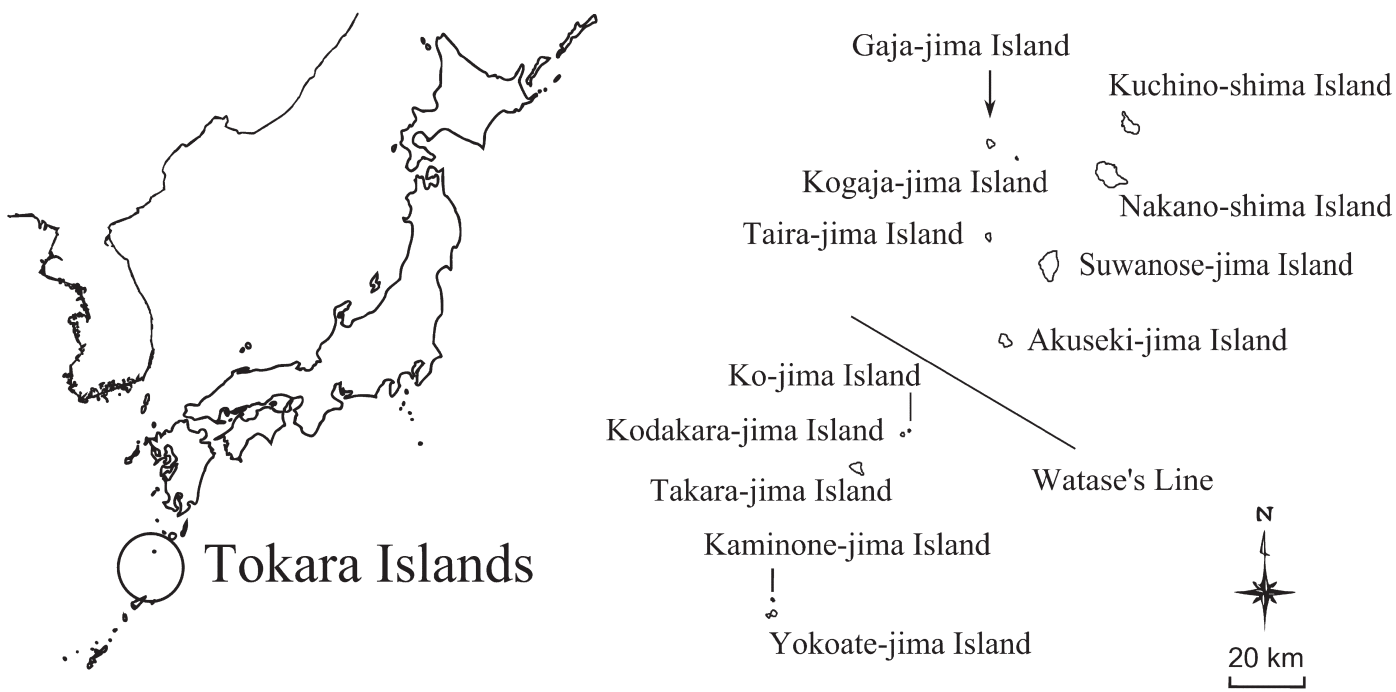

Fig. 1. Map of the location of Gaja-jima Island in Japan. Left: the location of the Tokara Islands. Right: the location of Gaja-jima Island in the Tokara Islands.

subjects to biogeographical studies (e.g. Kato \& Yagi 2004, Nakamura et al. 2010). A hypothesized biogeographical boundary between Palearctic and Oriental regions called Watase's line has been recognized between Akuseki-jima Island and Kodakara-jima Island (Fig. 1).

We got a chance to investigate the ant fauna on one of these uninhabited islands, Gaja-jima Island $\left(29^{\circ} 32^{\prime} 24^{\prime \prime} N, 129^{\circ} 19^{\prime} 12^{\prime \prime}\right.$ ) (Fig. 1), which is located in the Palearctic zone, north to the Watase's line. The island is small $\left(4.07 \mathrm{~km}^{2}\right)$ and has $492.2 \mathrm{~m}$ height at maximum. People had lived on this island probably from $12^{\text {th }}$ century to 1970 (Kozono 1995). Since 1970, there have been no residents on the island, but landing has been made occasionally by people who maintain a lighthouse. Landing on the island is now restricted by Toshima Village.

There exist a few studies on the insect fauna on Gaja-jima Island (termites: Ikehara 1959, beetles: Matsushita 1999, Toki \& Hosoya 2012, butterflies: Fukuda 2007, mosquitoes: Noda 2011). Environmental degradation on the island is a concern because of increased populations of two introduced vertebrate herbivores, Sika Deer (Cervus nippon mageshimae Kuroda and Okada) and domestic goat (Carpa hircus Linnaeus) (Terada 1999).

This article reports on the ground-dwelling ant fauna on Gaja-jima Island. Ants are easily collected, identified, and an indicator group of biodiversity (Alonso 2000), but no faunal investigations of ants, to our knowledge, have been conducted on this island. As exotic ants often invade new areas accompanied with human activities, it would be worth to examine in future studies the differences in ant fauna between inhabited and uninhabited islands in the Tokara Islands (Holway et al. 2002).

\section{Material and methods}

Gajia-jima Island is a small volcanic island surrounded by a sea cliff more than $100 \mathrm{~m}$ in height. The flora of this island reaches up to 408 species of plants (Terada 1999). Most parts of the island are covered with Pleioblastus linearis Nakai 1925 (Poaceae) bamboos especially on the west side where residents had lived, whereas rich forests exist on the east side (Terada 1999). A paved road runs from the landing point to a lighthouse and collections of ground-dwelling ants were mainly made along this road (in about $2 \mathrm{~m}$ width out from each side of the road). The region around the road was divided into three areas based on three major environments along the road: entrance, former village, and lighthouse. Dry and 


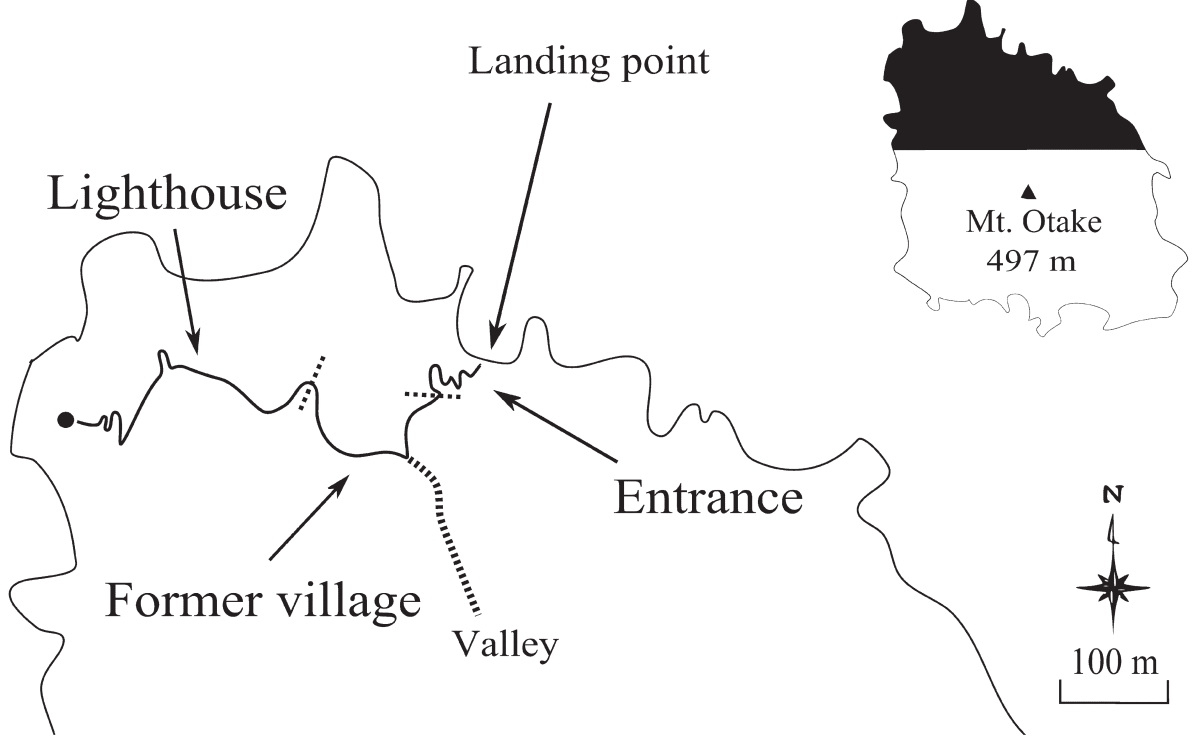

Fig. 2. Detailed map of the research areas on Gaja-jima Island. Solid line represents the paved road investigated. "Lighthouse", "Entrance", and "Former village", separated by dotted lines perpendicular to the solid line, show different subsets of the investigated area. The dashed line stretching southeast from the southernmost tip of the road represents the dry-up valley which is included as a part of the "Former village" area. The solid circle represents the lighthouse.

open grasslands spread in the entrance and lighthouse areas. The lighthouse area was also surrounded by a bamboo thicket. In contrast, many shrubs and trees covered the sampling site in the former village area, creating relatively moist and dark environments. The trees were mainly Pinus thunbergii Parl. 1868 (Pinaceae), Ardisia sieboldii Miq. 1867 (Myrsinaceae) and Machilus thunbergii Siebold \& Zucc. 1846 (Lauraceae). A dry valley in the former village area was also searched for the ants (Fig. 2). This valley was covered with trees like $A$. sieboldii, M. thunbergii and Castanopsis sieboldii (Makino) Hatus. 1971.

Ant collections on Gaja-jima Island under the permission from Toshima Village were carried out during an 8 hours visit (from 8 a.m. to 4 p.m.) on 13.VII.2011. The sampling was restricted because of only a day-time permission for a one-day visit. Ant foragers walking on the ground were haphazardly collected using an aspirator. Decaying woods, grounds under stones, and slopes along the road were also searched for ant colonies. Because the number of individuals we could collect was restricted to about 10 individuals for each species by the permit, only some workers, queens and males if available were caught even if a whole colony was found.

All ants collected were identified to species and classified into native or exotic species based on taxonomic literatures by M. K. (Onoyama 1980, Yamane et al. 1999, Onoyama \& Yoshimura 2002, Japanese Ant Database Group 2007, Yoshimura \& Onoyama 2007, Yoshimura et al. 2009, Katayama \& Tsuji 2010). Voucher specimens are deposited at the Entomological Laboratory of University of the Ryukyus.

\section{Results}

Twenty-three ground-dwelling ant species were found on Gaja-jima Island: 2 in the subfamily Ponerinae, 1 in Proceratiinae, 14 in Myrmicinae, 1 in Dolichoderinae, and 5 in Formicinae (Table 1). Among them, 4 species were recorded in the Tokara Islands for the first time: Proceratium ito A. Forel, 1918, Aphaenogaster famelica (F. Smith, 1874), Aphaenogaster japonica A. Forel, 1911, and Camponotus yamaokai Terayama et Satoh, 1990. The other 19 species have been re- 
Table 1. List of ant species collected on Gaja-jima Island with regions of distributions ( $E$, exotic; $O$, Oriental; $P$, Palaearctic), sites of collection ( $E$, entrance; $V$, former village; $L$, lighthouse), types of sampled specimens ( $F$, forager; C, colony), numbers of specimens collected (W, workers; $Q$, queens; $M$, males; minor and major workers were separated for Pheidole as minors+majors). Collectors (Leg.): TH, T. Hosoya; MK, M. Katayama; WT, W. Toki. V-No. is for the number of the voucher specimen and stars $\left(^{*}\right)$ denote species new to Tokara Islands.

Species

Region Site Type

Numbers

Leg. V-No.

$$
\text { W } \quad \text { Q M }
$$

Ponerinae

Hypoponera nippona F. Santschi, 1937

Ponera tamon Terayama, 1996

Proceratiinae

*Proceratium itoi A. Forel, 1918

Myrmicinae

*Aphaenogaster famelica (F. Smith, 1874)

${ }^{*}$ A. japonica A. Forel, 1911

A. osimensis Teranishi, 1940

A. tokarainsulana Watanabe et Yamane, 1999

Carebara yamatonis (Terayama, 1996)

Monomorium chinense Santschi, 1925

Pheidole fervens F. Smith, 1858

Ph. pieli Santschi, 1925

Pristomyrmex punctatus F. Smith, 1860

Solenopsis japonica Wheeler, 1928

Strumigenys lewisi Cameron 1886

Temnothorax anira (Terayama et Onoyama, 1999) Tetramorium bicarinatum Nylander, 1846

Vollenhovia benzai Terayama et Kinomura, 1998

Dolichodelinae

Tapinoma melanocephalum Fabricius, 1793

Formicinae

Acropyga sauteri A. Forel, 1912

Camponotus devestivus Wheeler, 1928

${ }^{*}$ C. yamaokai Terayama et Satoh, 1990

Nylanderia amia (H. Forel, 1913)

N. ryukyuensis (Terayama, 1999)
$\mathrm{P}, \mathrm{O}$

$\mathrm{P}, \mathrm{O}$

$\begin{array}{ll}\mathrm{O} & \mathrm{V} \\ \mathrm{O} & \mathrm{V} \\ & \mathrm{V}\end{array}$

F
C
F

$\mathrm{P}, \mathrm{O} \quad \mathrm{V} \quad \mathrm{F}$

$P$

P

$\mathrm{P}, \mathrm{O}$

$\mathrm{P}, \mathrm{O}$

$\mathrm{P}, \mathrm{O}$

$\mathrm{P}, \mathrm{O}$

$\mathrm{E}$

$\mathrm{P}, \mathrm{O}$

$\mathrm{P}, \mathrm{O}$

$\mathrm{P}, \mathrm{O}$

, O

$\mathrm{P}, \mathrm{O}$

$V$

P,O

E

$\mathrm{P}, \mathrm{O}$

$\begin{array}{ll}\text { V } & C \\ \text { V } & F \\ \text { V } & C \\ \text { V } & C\end{array}$

$\begin{array}{ll}\text { C } \\ \text { F } \\ \text { C } \\ \text { C } \\ \text { F } \\ \text { C } \\ \text { C } \\ \text { F } \\ \text { C } & \\ \text { C } & 6+7 \\ \text { F } & 4+1 \\ \text { C } & 7+3 \\ \text { C } & \end{array}$

$\begin{array}{lll}1 & 1 & 0 \\ 1 & 0 & 0 \\ 4 & 0 & 0\end{array}$

2

MK 16

TH 23

MK 31

MK 37

MK 8

MK 1

MK 34

MK 5

MK 21

MK 33

MK $\quad 30$

MK 25

MK 39

MK 10

MK 14

MK 29

MK 45

MK 3

MK 13

MK 28

MK 43

MK 44

MK 35

MK 32

MK 38

MK 4

MK 11

MK 17

MK 40

E V F

MK

19

$\mathrm{P}, \mathrm{O}$

V

V

$\mathrm{P}, \mathrm{O}$

$\mathrm{P}$

$\mathrm{P}, \mathrm{O}$

E

$\mathrm{P}, \mathrm{O}$

L

C
C
C
F
C
C
C
F
F

$\begin{array}{lr}\text { MK } & 15 \\ \text { MK } & 26 \\ \text { TH } & 27 \\ \text { WT } & 22 \\ \text { MK } & 42 \\ \text { MK } & 9 \\ \text { MK } & 20 \\ \text { MK } & 24 \\ \text { MK } & 36 \\ \text { MK } & 41\end{array}$


Table 2. Numbers of ant species recorded on each of the Tokara Islands. Information is based on Yamane et al. (1999), except for Gaja-jima Island.

\begin{tabular}{lccccc}
\hline & \multicolumn{3}{c}{ Numbers of ant species } & island area \\
\cline { 2 - 4 } & Total & $\begin{array}{c}\text { Ground- } \\
\text { dwelling }\end{array}$ & Exotic (\%) & Residents \\
\hline Kuchino-shima & 33 & 29 & $7(24.1)$ & 13.33 & + \\
Nakano-shima & 33 & 29 & $7(24.1)$ & 34.47 & + \\
Suwanose-jima & 13 & 12 & $3(25)$ & 27.66 & + \\
Taira-jima & 11 & 8 & $3(37.5)$ & 2.08 & + \\
Akuseki-jima & 24 & 18 & $4(22.2)$ & 7.49 & + \\
Takara-jima & 33 & 28 & $8(28.6)$ & 2.76 & + \\
Yokoate-jima & 15 & 13 & $3(23.1)$ & 4.07 & - \\
Gaja-jima & 23 & 22 & $3(13.6)$ & 0.36 & + \\
Ko-jima & 3 & 3 & $1(33.3)$ & 1 & + \\
Kodakara-jima & 4 & 2 & $0(0)$ & & + \\
\hline
\end{tabular}

1) The not ground-dwelling genera Amblyopone, Crematogaster, and Camponotus are excluded.

corded before on other islands of the Tokara Islands which comprise a total of 41 ground-dwelling ant species.

The number of species collected in the open entrance area, the forested former village area, and the open lighthouse area (Fig. 2) were 9, 17, and 3 respectively. Three exotic species, Pheidole fervens F. Smith, 1858, Tetramorium bicarinatum Nylander, 1846, and Tapinoma melanocephalum Fabricius, 1793, were obtained from the entrance and/or former village areas (Table 1).

\section{Discussion}

Of the 23 ground-dwelling ant species found on Gaja-jima Island, 3 (13\%) have been recorded only from the Palearctic region and 20 (86.9\%), including the three exotic species, have distributions on the both sides of the Watase's line (Table 1). Accordingly, all but three ant species found in this study were distributed regardless of Watase's line. Although Watase's line have been postulated as the boundary between Palearctic and Oriental regions for animal geographical distributions (Kuroda 1939), ants often have wide distributions in the Ryukyu archipelagos (Yamane et al. 1999). While A. famelica, A. japonica, and C. yamaokai had their southern distribution limit on Yakushima Island before this study (Yamane et al. 1999), they were also found to be on Gaja-jima
Island. Because the Tokara Islands are not oceanic islands, the three species could have existed on Gaja-jima Island before it was isolated geographically from the main land of Japan, including Yaku-shima Island. These results suggest that Watase's line might have no clear meaning on geographic distributions of ants.

The three exotic ants recorded from Gajajima Island are widely distributed in the Tokara Islands: $P$. fervens and T. bicarinatum on $\mathrm{Ku}-$ chino-shima, Nakano-shima, Suwanose-jima, Taira-jima, Akuseki-jima, Takara-jima and Yokoate-jima islands, and T. melanocephalum on Kuchino-shima, Nakano-shima, Suwanose-jima, Taira-jima and Takara-jima islands. Gaja-jima Island showed the lowest percent $(13.6 \%)$ of exotic species compared to most other islands (13.6 $37.5 \%$ ), except for two islands having only few ant species (Table 2). Because exotic ants often reproduce and migrate without flights (Holway et al. 2002), human activities would be required to spread their distributions from an island to another. Minor human activities, such as lighthouse repairing, should have small contributions to the invasion of exotics, because it cannot carry large stuffs hiding a fraction of a colony. Ants can spread their distributions over a sea also by rafting (Abe et al. 2012). However, rafting to Gajajima Island from other islands is not very likely, because the Kuroshio Current flows from the west to the east of the Tokara Islands. Some ex- 
otic ants in the Ryukyu archipelago were recorded in the early years of the 20th century. For instance, the invasive yellow crazy ant, Anoplolepis gracilipes F. Smith 1857, was found on Amami-Oshima Island in 1930 (Wetterer 2005). Though the precise information on the date the three exotic species invaded is not available, the chance that those three species invaded before 1970 is relatively high compared to that it happened after 1970, because human activities by inhabitants on Gaja-jima Island practically ceased by 1970 . Therefore, it would be most likely that the three Gaja exotics invaded Gaja-jima Island already before left by residents.

Information about the ant fauna on the Tokara Islands is insufficient, including this preliminary report on ground-dwelling ants of Gaji-jima Island. Accordingly, more detailed surveys are needed to clarify distributional differences of ant fauna among islands in the Ryukyu archipelago.

Acknowledgements. We wish to thank Dr. M. Tanahashi for his help with the field survey, the staff of the guest-house of Nagoran-sou and the crew of a fishing boat of Kaito-maru II for their help with conducting the field survey. We are grateful to Toshima Village for allowing us to collect specimens and giving landing permission on Gaja-jima Island. M. K. was partly supported by Mitsui-Bussan Environmental Funds (No. 08R-B047) to H. Tatsuta. W. T. was supported by Fujiwara Natural History Foundation. Two anonymous reviewers greatly improved this manuscript.

\section{References}

Abe, T., Yamane, S. \& Onoyama, K. 2012: Ants collected on the Krakatau Islands 100 years after the great eruptions. - Biogeography 14: 65-75.

Alonso, L. E. 2000: Ants as indicators of diversity. - In: Agosti, D., Majer J., Alonso, E. \& Schultz, T. R. (eds.), Ants: standard methods for measuring and monitoring biodiversity: 80-88. Smithsonian Institution Publications, Washington DC. 280 pp.

Fukuda, H. 2007: Autumnal mass flight of the powdered oakblue, Narathura bazalus (Hewitson) (Lepidoptera, Lycaenidae) observed on Gaja-Jima Is., Tokara lsls., southern Japan. - Transactions of the Lepidopterological Society of Japan 58: 91-96. [In Japanese with English abstract.]

Holway, D. A., Lach, L., Suarez, A. V., Tsutsui, N. D. \& Case, T. J. 2002: The causes and consequences of ant invasions. - Annual Review of Ecology and Systematics 33: 181-233.

Ikehara, S. 1959: The termite fauna of the Ryukyu Islands and its economic significance (IV) (Tokara-retto). -
Bulletin of Arts \& Science Division Ryukyu University (Mathematics \& Natural Sciences) 3: 43-51.

Japanese Ant Database Group 2007: Japanese Ant Image Database 2007. - [www database]. URL http:// ant.edb.miyakyo-u.ac.jp/IndexE/. (Cite visited on 18 July, 2012)

Katayama, M. \& Tsuji, K. 2010: Habitat differences and occurrence of native and exotic ants on Okinawa Island. - Entomological Science 13: 425-429.

Kato, Y. \& Yagi, T. 2004: Biogeography of the subspecies of Parides (Byasa) alcinous (Lepidoptera: Papilionidae) based on a phylogenetic analysis of mitochondrial ND5 sequences. - Systematic Entomology 29: 19.

Kozono, K. 1995: Toshima-sonshi, Editing Committee of Toshima-sonshi, Toshima, Japan. - Medieval Period in Tokara: 457-572.

Krell, F. 2000: Impact factors aren't relevant to taxonomy. — Nature 405: 507-508.

Kuroda, N. 1939: Distribution of mammals in the Japanese empire. - Journal of Mammalogy 20: 37-50.

Matsushita, T. 1999: Record of insect-collecting in uninhabited island "Gaja-jima Island, the Tokara Islands". Gekkan-Mushi 340: 86-97. [In Japanese.]

Myers, N., Mittermeier, R. A., Mittermeier, C. G., da Fonseca, G. A. B. \& Kent, J. 2000: Biodiversity hotspots for conservation priorities. - Nature 403: 853-858.

Nakamura, K., Denda, T., Kokubugata, G., Suwa, R., Yang, T. Y. A., Peng, C. \& Yokota, M. 2010: Phylogeography of Ophiorrhiza japonica (Rubiaceae) in continental islands, the Ryukyu Archipelago, Japan. Journal of Biogeography 37: 1907-1918.

Noda, S. 2011: Survey of mosquito larvae on Gaja Island, Toshima village, Kagoshima prefecture. - Occasional Papers in Kagoshima University Repository 51: 94-96. [In Japanese with English abstract.]

Onoyama, K. 1980: An introduction to the ant fauna of Japan, with a check list (Hymenoptera, Formicidae). Kontyu 48: 193-212.

Onoyama, K. \& Yoshimura, M. 2002: The ants of the genus Proceratium (Hymenoptera: Formicidae) in Japan. - Entomological Science 5: 29-49.

Pfeiffer, M., Mezger, D., Hosoishi, S., Yahya, B. E. \& Kohout, R. J. 2011: The Formicidae of Borneo (Insecta: Hymenoptera): a preliminary species list. — Asian Myrmecology 4: 9-58.

Terada, J. 1999: Shinnyu doubutu ga mujin-tou no syokusei ni ataeru eikyou. - Gaja-jima no syokubutsu-so to genson syokusei - [The impacts of exotic herbivorous vertebrates on the flora of an uninhabited island. - Flora and current vegetation in Gaja-jima Island]. - Minami-Nihon-Bunka 33: 59-108. [In Japanese.]

Toki, W. \& Hosoya, T. 2012: New host plant and southernmost records of asymmetric lizard beetle Doubledaya bucculenta Lewis (Coleoptera: Erotylidae: Languriinae). - Elytra New Series 1: 253-254.

Wetterer, J. K. 2005: Worldwide distribution and potential spread of the long-legged ant, Anoplolepis gracilipes (Hymenoptera: Formicidae). — Sociobiology 45: 77 97. 
Yamane, S., Ikudome, S., Terayama, M. 1999: Identification guide to the Aculeata of the Nansei Islands, Japan. Hokaido University Press, Japan, 830 pp.

Yoshimura, M. \& Onoyama, K. 2007: A new sibling species of the genus Strumigenys, with a redefinition of S. lewisi Cameron. - Advances in ant systematics (Hymenoptera: Formicidae): homage to E. O. Wilson
50 years of contributions, American Entomological Institute, Gainesville: 664-690.

Yoshimura, M., Hosoishi, S., Kuboki, Y., Onoyama, K. \& Ogata, K. 2009: New synonym and new Japanese record of the ant genus Ponera (Hymenoptera: Formicidae). - Entomological Science 12: 194-201. 